\title{
DENÚNCIA E ALTERIDADE: OS QUADRINHOS DE VIAGEM DE GUY DELISLE
}

\section{Mateus Yuri Passos}

\section{DESCOBERTA, EXPERIÊNCIA E A VERTIGEM DOS GENNEROS}

Nos textos que introduzem este volume, assim como em um artigo que publiquei anteriormente (PASSOS e CASTILHO, 2017), é fortemente ressaltada a noção de que há um núcleo temático comum às narrativas de viagem: a descoberta - e, mais especificamente, a descoberta do outro, em um exercício de alteridade. Assim, torna-se evidente que a literatura de viagem não se centra necessariamente apenas sobre localidades, mas também sobre povos, sobre civilizações.

O tema é um dos elementos essenciais - junto a forma composicional e estilo - para se definir gêneros de texto (e não apenas de texto) a partir da concepção bakhtiniana de gêneros discursivos, bastante cara a mim justamente por sua elasticidade e - por que não? - permissibilidade, ao proporcionar a visão de uma cosmologia de gêneros que em vez de restringi-los a um conjunto definido e bem delimitado, abre a portas para o infinito, a ponto de nos passar alguma uma sensação de vertigem: para Bakhtin (2016), ao mesmo tempo que um conjunto de práticas discursivas que utilizem com alguma recorrência e estabilidade elementos temáticos, composicionais e estilísticos semelhantes configuraria um gênero discursivo, qualquer alteração substancial em um desses componentes necessariamente originaria um novo gênero, necessariamente distinto do primeiro.

* Professor do Programa de Pós-Graduação em Comunicação Social da Universidade Metodista de São Paulo (Umesp) e editor da revista Comunicação \& Sociedade. Doutor em Teoria e História Literária pela Universidade Estadual de Campinas (Unicamp). Mestre em Ciência, Tecnologia e Sociedade pela Universidade Federalm de São Carlos (UFSCar). Bacharel em Jornalismo pela Pontifícia Universidade Católica de Campinas (PUC-Campinas) e em Estudos Literários pela Universidade Estadual de Campinas (Unicamp). E-mail: mateus.passos@metodista.br 
Assim, numa perspectiva bakhtiniana pode fazer mais sentido falar em sistemas de gêneros discursivos do que em gêneros isolados e bem delimitados, prevendo assim a variação, a dissonância, os pontos fora da curva e, principalmente, os pontos fora da curva que fazem escola, vão se aglomerando e passam a constituir seus próprios conjuntos (ou subsistemas) de gêneros discursivos - assim, podemos trabalhar definições que compreendam e mesmo antecipem simultaneamente a semelhança e a diferença. Essa é, por exemplo, a tratativa com que venho trabalhando o jornalismo literário (PASSOS, 2017), especialmente diante do enorme desafio encontrado pelos pares em encontrar uma definição globalizante que permitisse classificá-lo enquanto gênero ou forma em suas múltiplas e radicalmente distintas encarnações ao redor do mundo e ao longo das décadas e séculos (BAK, 2011): pensá-las como um sistema de gêneros discursivos que tem como ponto comum um elemento composicional - a hibridização entre práticas do jornalismo e da literatura - permite a aceitação do dissonante e do imprevisto, identificar a formação de subconjuntos de gêneros surgidos a partir de uma ou mais dessas dissonâncias - caso do jornalismo gonzo, que compreende práticas bastante distintas, mas ainda relacionadas, especialmente a partir da relação dialógica com os textos-referência do pioneiro, Hunter S. Thompson (MARTINEZ e PASSOS, 2018). Pensar conjuntos de gêneros também permite compreender como práticas semelhantes se relacionam entre distintos subconjuntos de gêneros: é possível, por exemplo, identificar obras que se encontram na zona fronteiriça, nos pontos de contato entre os subconjuntos de jornalismo gonzo e jornalismo literário de viagens, como as reportagens de Arthur Veríssimo para a revista Trip, histórias de perfomance egocêntrica centradas sobre o contato, o estranhamento e por vezes a empatia com diferentes culturas ao redor do mundo, com especial destaque para práticas religiosas.

Gostaria de pensar então, de forma bakhtianamente bastante preliminar, não exaustiva e não delimitadora, sem perspectivama de conclusão ou acabamento, as narrativas de viagem enquanto um conjunto bastante complexo e diverso de gêneros discursivos - diverso inclusive ao se compor de diversas e distintas linguagens narrativas, de diversos suportes midiáticos. $\mathrm{O}$ conjunto apresentado neste livro é uma exemplar amostra disso: há narrativas de viagem essencialmente textuais-documentais, essencialmente imagéticas, ficcionais, jornalísticas, publicitárias, audiovisuais, transmídia - e dentre elas não posso deixar de identificar as recentes narrativas de bicicleta de Demétrio de Azeredo Soster, Operação Banda Oriental (2017), Operação Valparaíso (2018) 
e Operação Carretera Austral (2019), que além de comporem conjuntos de livro e documentário, de narrações que complexamente se constroem juntamente e simultaneamente às experiências narradas, ainda constituem híbridos entre material de fruição e acadêmico ao receberem suas contrapartes acadêmicas.

Ainda temos, porém, aquele núcleo temático comum que nos permite agrupá-las - que além do deslocamento em si compreende, como já mencionado, a descoberta da outra terra e do outro povo, mas num nível ainda mais fundamental compreende a organização e narração da experiência pessoal, desde as suas origens nas narrativas dos poucos privilegiados que em tempos de grandes limitações infraestruturais tinham a possibilidade de desbravar o mundo (MARTINEZ, 2016).

A narração da experiência é um tópico caro a autores como Walter Benjamin, explorado em ensaios de sua fase madura como "Experiência e Pobreza" ["Erfahrung und Armut"], de 1933, e "O Contador de Histórias" ["Der Erzähler", mais conhecido no Brasil com o título "O Narrador"], de 1936 - mais especificamente, interessa a Benjamin a "pobreza de experiência" (2012, loc.1235), a decadência e desvalorização da experiência na produção narrativa das primeiras décadas do século XX, pela qual atribuia culpa ao menos parcial ao jornalismo de seu tempo (BENJAMIN, 2018). É preciso ter em mente que Benjamin se referia naquele momento a um processo de "modernização" do jornalismo que incorporava estratégias textuais como o lead e a estrutura de pirâmide invertida, buscando a redução dos acontecimentos aos seus núcleos factuais essenciais (GENRO FILHO, 2012) e a apreciação racional e emocional aos eventos a fragmentos declatórios - as formas de caráter narrativo-descritivo como o jornalismo literário se opõem diametralmente a isso, constituindo-se justamente como jornalismos que privilegiam a experiência como condição essencial de apreciação da realidade (PASSOS, 2017).

$\mathrm{Na}$ narrativas da experiência ao menos desde o final do século XIX, em movimentos literários como o naturalismo francês e o verismo italiano, assim como nos estudos acadêmicos de disciplinas como História (HELLER, 2016; CERTEAU, GIARD e MAYOL, 2013) e Filosofia da Linguagem (VOLOSHINOV, 2015), tem ganhado terreno e protagonismo a contemplação do cotidiano, em complemento ou mesmo substituição à narrativa dos grandes acontecimentos, dos grandes feitos. A vivência do cotidiano, as práticas rotineiras e banais, ou mesmo as rupturas da rotina na singular dimensão do indivíduo e das pequenas comunidades, a narração de tudo 
isso permite conhecer uma realidade frequentemente destoante dos grandes padrões e das considerações generalizantes sobre uma localidade, sobre um povo. Valentin Volóshinov (2015), em obra usualmente atribuída a Mikhail Bakhtin, chega a afirmar que a vivência do cotidiano dá origem mesmo a uma ideologia, uma cosmovisão própria, que se oporia a uma ideologia oficial, aquela constituída pelas instituições de poder administrativo, coercitivo e financeiro - privilegiar uma pintura narrativa de tal ideologia dialoga com o movimento pelo qual Benjamin (2012) faz um apelo na mais enigmática de suas obras, o conjunto de teses "Sobre o Conceito de História" ["Über den Begriff der Geschichte"]: escovar a História a contrapelo, desvelar aquilo que é ocultado pela escrita da história das grandes narrativas, da História dos vitoriosos, dos dominadores, da hegemonia. Quando falamos do cotidiano nas narrativas de viagens - as quais em teoria representariam uma ruptura com a dimensão a que mais usualmente atribuímos a noção de cotidianidade -, tratamos justamente das pequenas dimensões da vida que se desvelam, da observação de hábitos e valores distintos daquele do viajante que narra, do choque cultural, da mútua compreensão do outro e eventual assimilação de alguns desses hábitos e valores: enfim, pela troca cultura, pela alteridade nos seus aspectos mais fundamentalmente dialógicos e humanos.

Chegamos, finalmente, ao tópico da histórias em quadrinhos enquanto um dos suportes artísticos nos quais se articulam narrativas de viagem. Quadrinhos são também um complexo sistema de gêneros discursivos, com radicais variações temáticas e estilísticas, embora mais comumente conhecidos a partir das variações mainstream que Douglas Wolk $(2007$, p.21) denomina "quadrinhos de gênero" [Genre comics], segmentados em temáticas como terror, ação, fantasia, ficção científica e super-heróis, e geralmente considerados como material de leitura exclusivamente juvenil - é importante notar que a noção de gênero com que Wolk trabalha é essencialmente temática, embora naturalmente tenha suas consequências e limitações em termos composicionais e estilísticos, dimensões geralmente articuladas em torno das convenções das três grandes matrizes quadrinísticas globais: a anglo-saxônica, a europeia e a japonesa, cada qual evidentemente contendo um certo grau de hibridização com as demais a partir dos fluxos dialógicos entre as diferentes tradições e artistas. Para além dos "quadrinhos de gênero" abre-se o ainda mais vasto mundo de "quadrinhos artísticos" ou "quadrinhos de autor" (WOLK, 2007) que contempla ficção e não ficção, biografia e memória, naturalismo e surrealismo, o figurativo e o abstrato, o sóbrio e o onírico, abarcando obras 
tão díspares em estratégia narrativa - em seus aspectos visuais, assim como verbais - que chega a parecer extremamente redutor agrupá-las em torno de um denominador comum tão simplificador como "histórias em quadrinhos".

Mesmo quando falamos em quadrinhos de viagem, tratamos de um subconjunto de gêneros que abarca narrativas tão díspares que poderíamos considerá-las antípodas. Como exemplo, menciono duas obras pertencentes ao terreno da ficção e à mesma matriz, a japonesa: One Piece, mangá mainstream de Eiichiro Oda serializado semanalmente na Weekly Shonen Jump, a antologia de mangás de maior tiragem e popularidade no mundo dedicada ao público adolescente, e Um Bairro Distante [遥かな町へ, Haruka na Machi e], de Jiro Taniguchi, serializada na revista quinzenal Big Comic, voltada a um público mais maduro. One Piece é uma narrativa maximalista de ação e aventura, publicada desde 1997 e ainda inacabada, reunida até o momento em 93 volumes com uma média de aproximadamente 200 páginas, contendo o estilo narrativo cinemático e ágil que se tornou o padrão dos mangás desde as contribuições de Osamu Tezuka entre os anos 1950 e 1980 - narrando a história de um bando de piratas em uma jornada que literalmente dá a volta ao mundo, enfrentando inimigos cada vez mais poderosos enquanto lentamente vão se desvendando os mistérios do colapso de uma civilização esquecida e da emergência de um governo mundial hegemônico, a viagem é apenas um dos aspectos da narrativa, mas constitui justamente o elemento que confere alguma unidade à trama, com sucessivos deslocamentos entre países cujos habitantes, arquitetura, hábitos e valores são sempres caracterizados de forma peculiar e singularizante. Um Bairro Distante, por outro lado, é substancialmente menor em dimensão, compreendendo dois volumes com material publicado entre abril e novembro de 1998; menor também no escopo da trama, ao tratar de uma viagem de descoberta em um de seus aspectos mais banais, quando o protagonista por equívoco toma um trem para seu bairro natal, distante de sua residência, e ali revive memórias e confronta seu passado. Com um estilo visual e composição narrativa mais próxima do modelo de álbuns da matriz europeia de quadrinhos, muitas das obras mais renomadas de Jiro Taniguchi se focam justamente nas jornadas sem grandes eventos significativos de um protagonista flanêur que explora vizinhanças desconhecidas, ou mesmo ruas desconhecidas de sua vizinhança, como em O Homem Que Passeia [歩くひと, Aruku Hito] ou desbrava restaurantes, pratos e sabores como em O Gourmet Solitário. [孤独のグルメ,Kodoku no Gurume]. As jornadas nas histórias de Oda dão passos largos, têm escopo monumental e 
guardam o potencial de mudar os rumos da humanidade de todo um mundo, enquanto as de Jiro Taniguchi são tímidas e, se têm algum impacto, esse se dá apenas no íntimo de seus protagonistas.
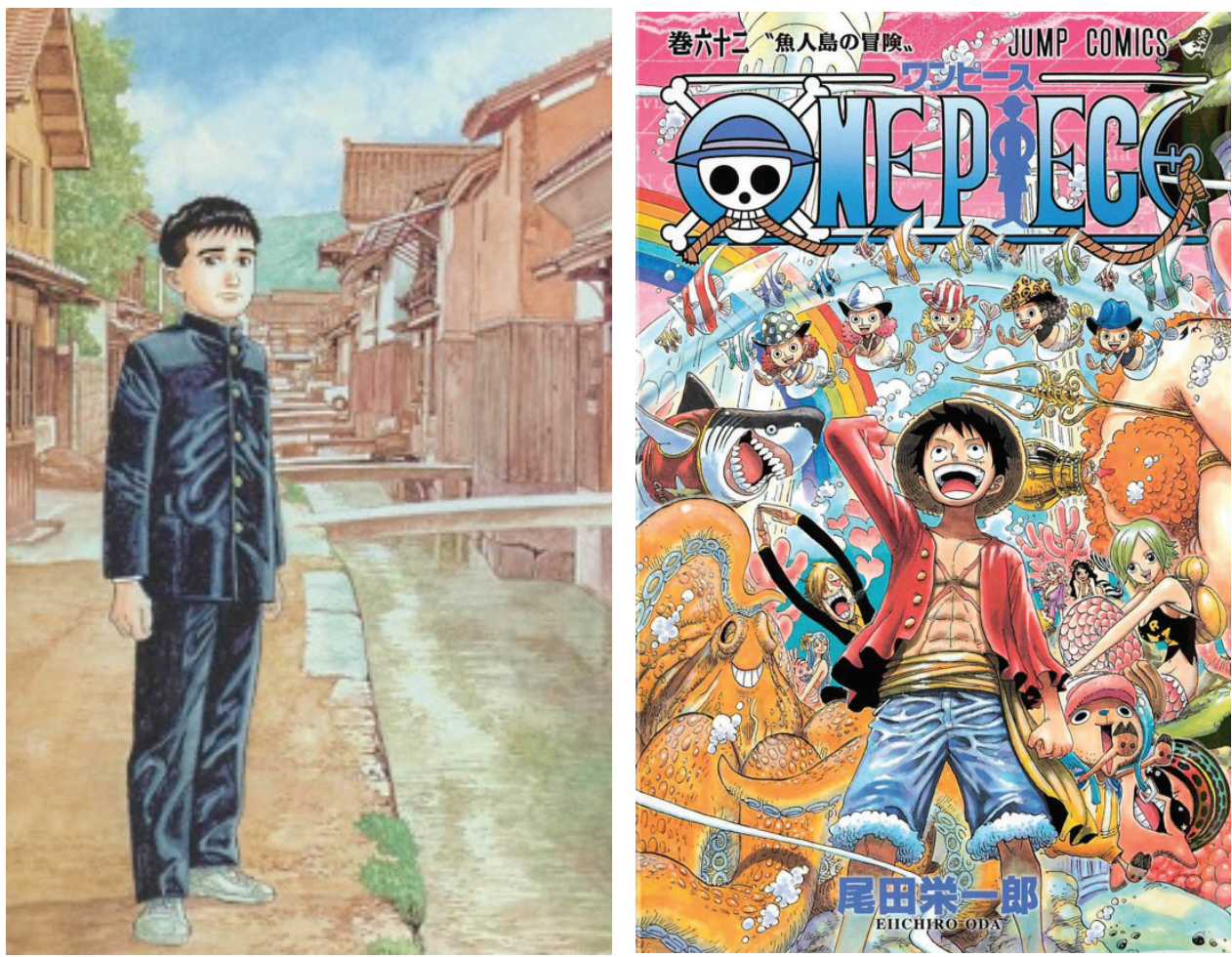

Figuras 1 e 2: Um Bairro Distante e One Piece: quadrinhos japoneses contemporâneos em que estilo, composição e a própria noção de viagem são radicalmente distintos.

No terreno da não ficção, obras que contemplam e celebram a dimensão do cotidiano são bem mais recorrentes, terreno desbravado pelo norte-americano Harvey Pekar nos anos 1970 ao tratar, em sua série American Splendor, de temas como suas obsessões pessoais, o incômodo com filas de supermercado ou a apreciação de discos de jazz (VILELA, 2016) ou pela também norte-americana Alison Bechdel em obras como Fun Home e Você é Minha Mãe? [Are You My Mother?] (ZOUVI, 2016).

Se pensamos em narrativas de viagem de não ficção em quadrinhos - já contemplando intersecções entre diversos subconjuntos desse vasto sistema 
de gêneros discursivos -, um dos expoentes no segmento de caráter mais jornalístico é o maltês Joe Sacco, foco do capítulo de Ricardo Jorge neste livro, especializado em cobertura de guerra e globalmente reconhecido por seus trabalhos focados na questão palestina e na Guerra dos Bálcãs.

Outro nome que vem se singularizando e ganhando destaque no campo será o foco de nossa atenção aqui: Guy Delisle, que se especializou em trabalhos de caráter autobiográfico e em certa medida denuncista, embora os mais recentes tenham ganhado uma dimensão mais favorável à humanização e alteridade. Como toda narrativa de viagem, as quatro narrativas que discutiremos brevemente aqui - Shenz̧hen, Pyongyang, Crônicas Birmanesas e Crônicas de Jerusalém - são, assim, narrativas da descoberta do outro, narrativas da experiência e do cotiano. Enquanto conjunto, porém, elas constituem uma espécie de narrativa de formação em que acompanhamos o gradual amadurecimento do sujeito narrador, de suas visões de mundo e de sua relação com o Outro que se apresenta em suas vivências em terras estrangeiras.

\section{GUY DELISLE: AS NARRATIVAS DO CHOQUE E DA EMPATIA}

Guy Delisle é um quadrinista e cartunista franco-canadense, nascido na cidade de Quebec, situada na província de mesmo nome. Sua formação artística e acadêmica inicialmente foi voltada ao campo da animação, trabalhando então para estúdios no Canadá e posteriormente na França. Quando se muda para a Europa, passa também a publicar histórias em quadrinhos - pela editora L'Association, especializada em quadrinhos autorais, passa a publicar trabalhos de ficção como Réflexion (1996), Aline et les Sutres (1999) e Albert et les Autres (2001), trabalhos ficcionais compostos por sequências puramente visuais, sem a interação dos desenhos com um texto verbal. Seu trabalho de ficção continuaria com os três volumes de Inspecteur Moroni (2001, 2002 e 2004), e os livros infantis Louis au Ski (2005) e Louis à la plage (2008), narrativas compostas a partir de uma mescla de suas recordações de infância e das observações que fez de seu próprio filho Louis.

Logo a não ficção - dentro dos limites em que é possível negar a ficcionalização dos relatos, como veremos na terceira seção deste capítulo passaria a ser a principal senda narrativa de Delisle, especialmente a partir do momento em que, trabalhando como diretor de animação para sucursais asiáticas de estúdios franceses, passa a experienciar culturais e modelos de sociedade bastante distintos daqueles a que se habituara. Assim, já o seu terceiro álbum lançado pela L'Association passaria a ser uma verdadeira 
graphic novel, um romance gráfico, história em quadrinhos de maior fôlego, e também sua primeira narrativa de viagem: Shenz̧hen (2000), um relato de sua estada de três meses na China, trabalhando no estúdio de animação. A experiência na Coréia do Norte renderia a graphic novel Pyongyang (2003), em muitos aspectos bastante semelhante à primeira.

O amadurecimento da abordagem narrativa de Delisle, de seu estilo e mesmo de seu envolvimento com as localidades se transformaria radicalmente a partir do momento em que mudam as condições de seu deslocamento e permanência nas localidades. Quando começa a namorar e posteriormente se casa com Nadège, administradora que trabalha para a organização Médicos Sem Fronteiras, Delisle passa a viajar em função do trabalho da companheira e do cuidado dos filhos. A família vive em Myanmar/Birmânia em 2005, experiência narrada em Chroniques Birmanes [Crônicas Birmanesas] (2007), e em Israel entre 2008 e 2009, período recriado no livro Chroniques de Jérusalem [Crônicas de Jerusalém] (2011). O cotidiano do cuidado com o filhos deu origem à série de quadrinhos Le Guide du Mawvais Père [O Guia do Pai Péssimo], com quatro volumes publicados até o momento - em inglês, as obras receberam títulos distintos: A User's Guide to Neglectful Parenting, Even More Bad Parenting Advice, The Owner's Manual to Terrible Parenting e The Handbook to Lazy Parenting. Já a conviência com os profissionais da organização Médicos Sem Fronteiras renderia a graphic novel S'Enfuir. Récit d'un Otage [Fugir. O Relato de um Refém] (2016), que conta a história de Christophe André, um administrador dos Médicos Sem Fronteiras que foi sequestrado e viveu em cativeiro na região do Cáucaso em 1997.

As quatro graphic novels de Guy Delisle que constituem narrativas de viagem, relatos de sua experiência no estrangeiro - Shenz̧hen, Pyongyang, Crônicas Birmanesas e Crônicas de Jerusalém - têm uma estrutura narrativa peculiar: são quadrinhos-fragmento, quase fractais, compostos por pequenos instantâneos que representam momentos distintos de sua viagem - abordagem possivelmente influenciada pelo exercício de formas cartunescas curtas como as dos primeiros livros que produziu. São, assim, mais do que tramas de fôlego estruturadas num crescendo narrativo, coletâneas de experiências integradas por pequenas unidades sem progressão de ação, cuja tensão narrativa é rapidamente resolvida: um mosaico que representa de certo modo a natureza da experiência de viagem, na qual eventos se sucedem sem que haja conexão direta entre eles, a não ser a sequência cronológica. 

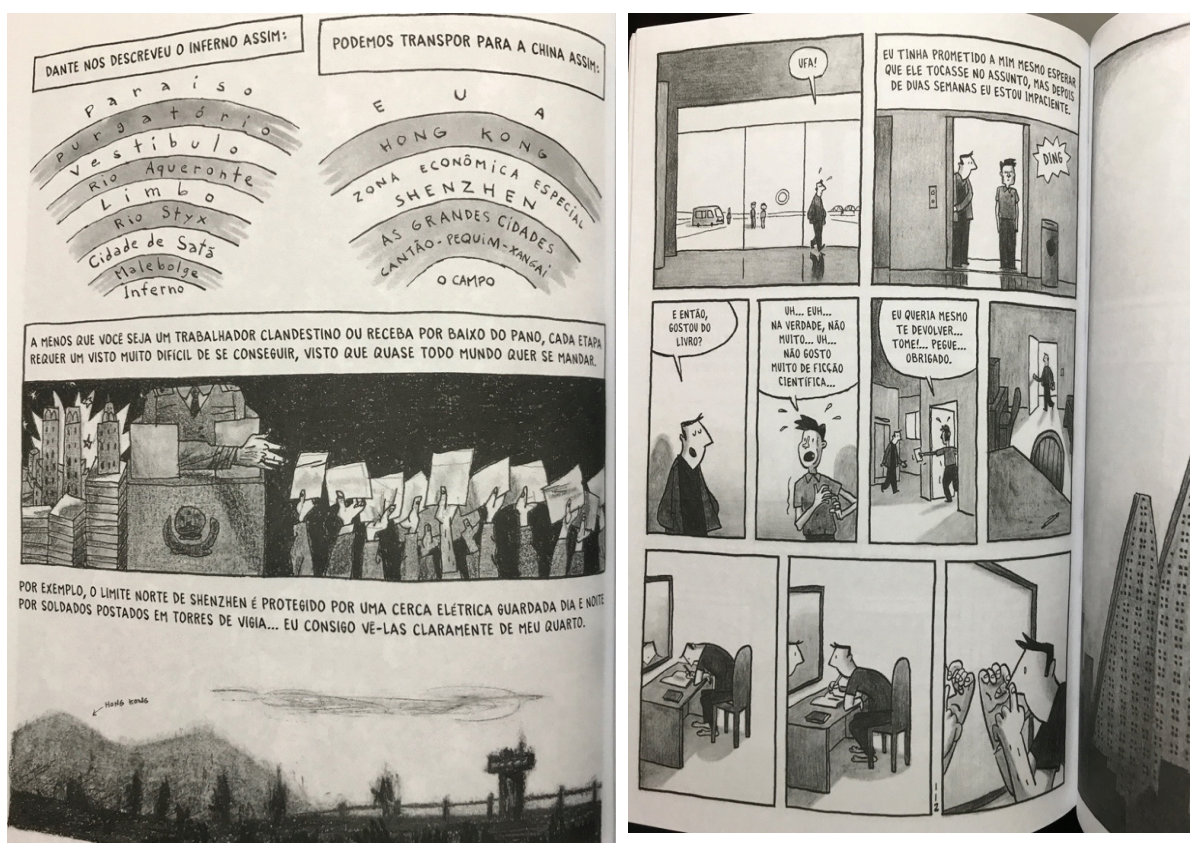

Figuras 3 e 4: Em Shenz̧hen (à esquerda) e Pyongyang (à direita), Delisle apresenta diversas formas de repúdio/denúncia de sociedades que rejeita, considerando-as não-lugares.

Os dois primeiros álbuns, Shenzhen e Pyongyang, como mencionado anteriormente, são bastante semelhantes, tanto na temática dos fragmentos narrativos quanto na responsividade de Delisle frente aos acontecimentos, aos ambientes. Em sua primeira experiência numa sociedade politicamente fechada, o cartunista manifesta na narrativa um choque cultural que o mostra horrorizado com a vida e sociedade locais - a ponto de compará-la diretamente com o Inferno dantesco da Divina Comédia, sintomaticamente elencando os Estados Unidos como análogos ao Paraíso (Figura 3). Esse gesto expressa uma percepção discursivo-ideológica que curiosamente aprecia os EUA como expressão máxima de liberdade civil, à qual se contraporia a sociedade chinesa, a medida a partir da qual os mais variados eventos - matricular-se em uma academia, passar o Natal com um colega de estúdio, a estada no hotel - tornam-se palco para expressar deslocamento, descontentamento e repúdio e pintar a cidade como um pesadelo vivo. Como apontam Dalmonte e Araujo (2011), esse movimento de rejeição se expressa no próprio traço de 
Delisle que, adotando um aspecto mais grosseiro, "reconstrói as percepções da sujeira, da palidez, da velocidade e, muitas vezes, do caos de Shenzhen" (DALMONTE e ARAUJO, 2011, p.357)

De forma semelhante, Pyongyang expressa o estranhamento e o repúdio de Delisle a sua estada de dois meses na capital norte-coreana. Há algumas distinções interessantes, porém. A primeira é o dúbio vínculo que o cartunista estabelece com seu guia permanente, Sin - a quem apelida Capitão Sin, de modo a prover algum alívio cômico para sua própria estada e para a narrativa. Desta vez, se há cenas em que a rejeição cultural-ideológica se coloca de maneira ainda mais intensa, como uma visita feita Museu Internacional da Amizade, uma celebração da revolução e dos líderes norte-coreanos, ou na qual tenta "despertar" um de seus guias ocasionais ao lhe emprestar um exemplar de 1984, de George Orwell - na esperança de que ele enxergasse os paralelos entre a realidade ao seu redor e a distopia orwelliana (Figura 4) -, há momentos de leveza em que Delisle se diverte com os guias ou colegas estrangeiros do estúdio de animação.
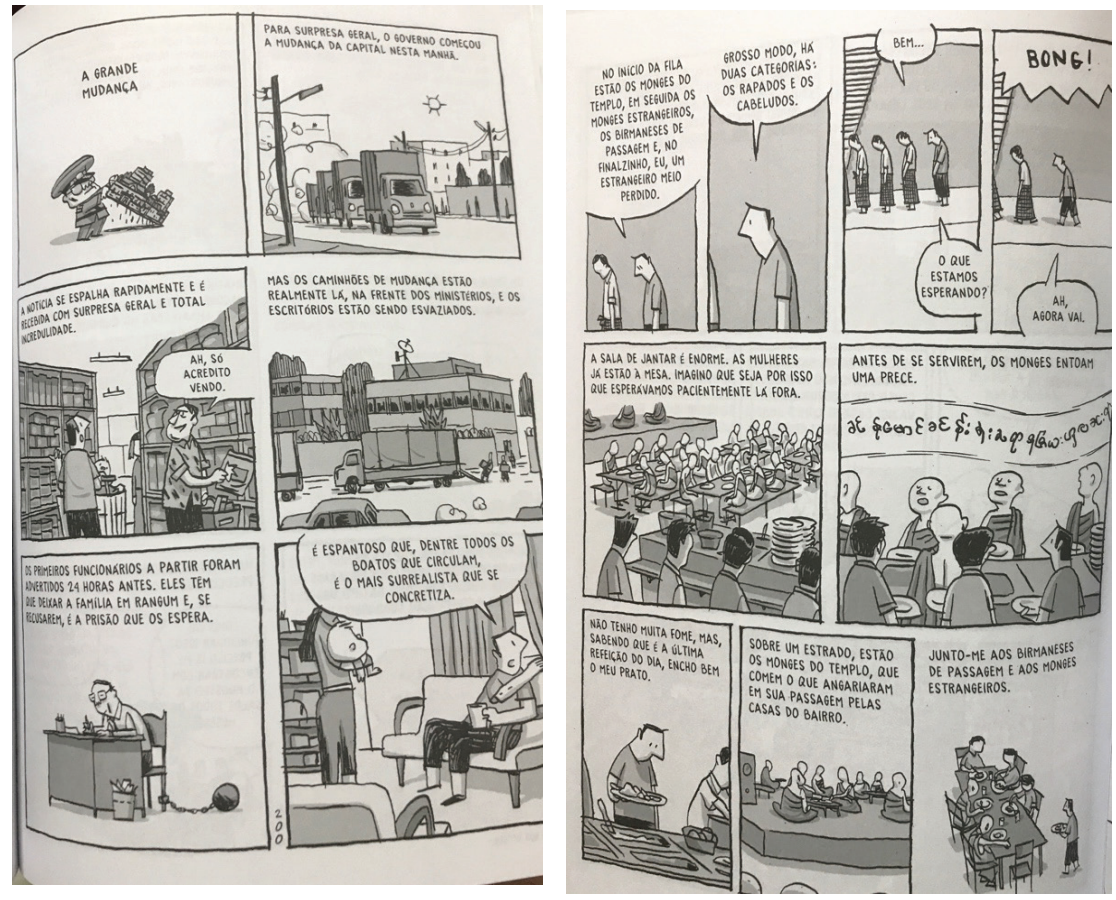

Figuras 5 e 6: Em dois momentos distintos de Crônicas Birmanesas, Delisle realiza um movimento de denúncia (à esquerda) da mudança súbita da capital da Birmânia, mas também de integração e envolvimento com a cultura local (à direita). 
Uma mudança substancial no tom narrativo é operada nas duas obras posteriores. Como mencionei anteriormente, Crônicas Birmanesas é um divisor nas narrativas de viagem de Delisle uma vez que o cartunista deixa de viajar movido pela priorização de seu próprio trabalho e passa a acompanhar Nadège em suas missões para os Médicos Sem Fronteiras. A estada na Birmânia/ Myanmar é assim marcada por uma mudança essencial na sua condição, na qual a maior parte das horas de seus dias não é preenchida pelo trabalho em estúdios de animação. Nadège assume o papel de protagonista que vai para onde a ação está (embora seja pouco presente nas cenas do livro), enquanto Delisle se ressignifica enquanto um flâneur que passa a explorar, desbravar a sociedade birmanesa.

Embora haja, como nos livros anteriores, gestos de denúncia e repúdio ao governo local, militarizado e autoritário a ponto de promover uma súbita e forçada mudança de capital nacional durante a estada do cartunista (Figura 5), Delisle passa a observar e retratar a cultura local de forma por vezes curiosa, por vezes respeitosa, buscando observá-la em sua distinção de um modo que dista bastante do absoluto repúdio por costumes e manias manifesto em Shenz̧̧en e Pyongyang: mesmo o hábito de mascar o bétel, uma planta local, que causa o manchamento dos dentes - aspecto que despertaria seu nojo nos contextos anteriores. Podemos compreender essa transformação a partir da mudança substancial nas condições que permitem o vínculo de Delisle com os espaços e as pessoas: sua permanência tem um caráter mais fortemente assemelhado à da residência, a criação de uma rotina do estabelecimento de um vínculo afetivo com a vizinhança (de CERTEAU, GIARD e MAYOL, 2013). Também podemos relembrar a distinção que Marc Augé (1994) propõe entre lugares e não-lugares, estes decorrentes da condição contemporânea a que denomina sobremodernidade. Não-lugares, como são Shenzhen e Pyongyang, para Delisle, são pontos de passagem, vistos como meios e não como fins, nos quais o sujeito se detém por pouco tempo, deixando de notar as singularidades do espaço e dos sujeitos ali presentes, no quais não cria raízes; o estabelecimento de um efetivo vínculo de afeto transforma essa relação e promove uma nova descoberta do local e a curiosidade pelos seres humanos por trás dele.

Por fim, Crônicas de Jerusalém aprofunda esse movimento de aprofundamento do vínculo de Delisle com os lugares, expressando mais efetivamente alguns exercícios de alteridade. Em termos enunciativos, Delisle se diferencia de outros autores que abordaram o tema palestino - especialmente Joe Sacco 
e Harvey Pekar - e de si próprio, nas narrativas de viagem anteriores, ao não se apresentar como mediador da narrativa, ou sobrepor sua voz às dos demais, e sim narrar um estado inicial de ignorância e ingenuidade e seu processo de transformação transformação pessoal na tentativa de compreensão do complexo fenômeno palestino.

A representação gráfico-narrativa do autor parte de alguns pressupostos equivocados ou ingênuos que são frequentemente desmentidos ou relativizados por seus interlocutores - especialmente suas impressões iniciais do Estado de Israel enquanto uma instituição pacífica e benevolente, desenvolvendo gradativamente interesse e empatia pelo povo palestino; do mesmo modo, pontos de vista de judeus, muçulmanos e mesmo cristãos são apresentados num panorama complexo - efetivamente polifônico (BAKHTIN, 2010) ao não conduzir o leitor para conclusões definitivas e simplistas, realizando inclusive um esforço por vislumbrar momentos de convivência pacifica entre os diferentes grupos (Figura 8).
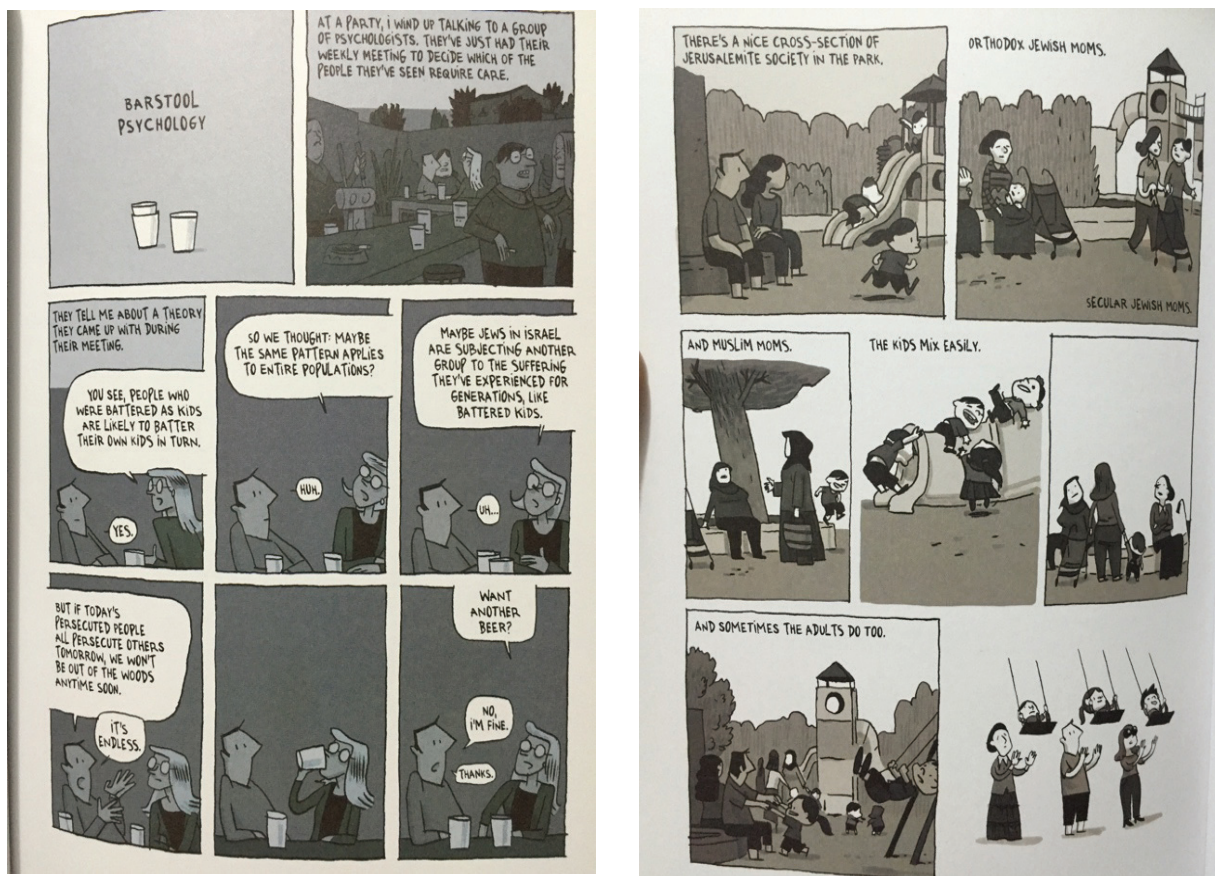

Figuras 7 e 8: Em dois momentos distintos de Crônicas de Jerusalém, Delisle expressa sua indignação com o ciclo vicioso de dominação e matança (à esquerda) e tem uma agradável surpresa ao notar, no cotidiano, movimentos de integração entre as diferentes culturas em Jerusalém (à direita). 
Em Crônicas de Jerusalém, é finalmente possível identificar em sua estratégia a emergência de uma valorização da experiência e da pluralidade pontos de vista das populações israelense e palestina, inclusive contemplando a diversidade cultural do país, que não se resume à polaridade entre judeus e muçulmanos. Embora haja uma presença importante dos Médicos Sem Fronteira, ela não se sobrepõe autoritariamente à fala popular e ambas contribuem para a composição de um complexo mosaico da questão palestina, das dificuldades de trânsito entre as localidades, de certo grau de paranóia israelense. Assim, nota-se um considerável amadurecimento do autor, ao optar por um esforço de compreender o contexto palestino, em vez de uma explicação causalista e simplificadora, do denuncismo de obras anteriores - pautada inclusive por uma representação narrativa desse mesmo amadurecimento, conforme constrói a si próprio enquanto personagem ingênuo que aos poucos descobre as contradições e armadilhas de um ciclo vicioso de dominação e matança contrário a qualquer esforço de redução ou simplificação (Figura 7). Novamente, um amadurecimento decorrente de uma experiência singular, na qual Delisle pôde efetivamente incorporar o lugar ao seu cotidiano, construir um vínculo com ele, uma relação de pertencimento e de afeto - especialmente ao casualmente conduzir seus filhos pela cidade de Jerusalém, ou manifestar maior interesse pelo território e se deslocar com mais frequência, ativamente buscando conhecer diferentes setores da sociedade, o que contemplou inclusive visitas a comunidades da Faixa de Gaza.

\section{SUBJETIVIDADE E REPRE-} SENTACÃO GRÁFICA

$\mathrm{Um}$ dos aspectos distintivos - que talvez estejam entre os mais relevantes - das narrativas de viagem é a preocupação com alguma recriação visual dos ambientes experienciados pelos viajantes- narradores, por vezes amparada por longas e detalhadas descrições. De acordo com John Hartsock

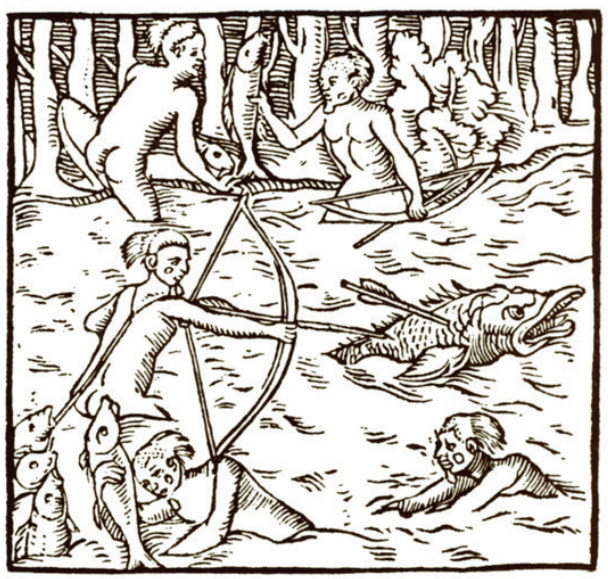

Figura 9: Gravura original de Duas Viagens ao Brasil, de Hans Staden, em que se retrata a cultura da pesca dos tupinambás. (PAPAVERO e TEIXEIRA, 2007) 
(2016), ao lidar com o jornalismo literário de modo específico, a combinação de narração e descrição permite ao leitor uma mais profunda imersão nos acontecimentos narrados, tornar-se uma espécie de testemunha virtual das ações, das pessoas e dos lugares, e desse modo envolver-se e mesmo assimilar melhor o material ali apresentado.

Essa preocupação já está manifesta em relatos medievais como Il Milione, de Marco Polo (MARTINEZ, 2016) e do início da idade moderna como a obra de Hans Staden publicada em 1557, Warbaftige Historia und beschreibung eyner Landtschafft der Wilden Nacketen, Grimmigen Menschfresser-Leuthen in der Newenwelt America gelegen [História verídica e descrição de uma terra de selvagens, nus e cruéis comedores de seres humanos, situada no Novo Mundo da América], tradicionalmente traduzida em português como Duas Viagens ao Brasil, na qual relata sua captura por uma comunidade Tupinambá, que praticava o canibalismo ritual, e seu papel como intérprete e mediador entre partes em conflito como seus captores e uma comunidade Tupiniquim, inimiga dos Tupinambás e aliada aos colonizadores portugueses. A obra apresenta diversas gravuras feitas pelo próprio Staden de modo a buscar reproduzir visualmente aquilo que vira e testemunhara em território brasileiro, nas imediações da atual Ubatuba, no litoral paulista. O trabalho narra-descritivo e iconográfico de Staden (Figura 9) é reconhecido pelo seu valor em ilustrar a flora e a fauna brasileira, assim como elementos do cotidiano dos Tupinambás com quem Staden conviveu (PAPAVERO e TEIXEIRA, 2007).

No caso dos quadrinhos, por conta de sua própria natureza composicional expressa na simbiose entre texto verbal de balões e recordatórios representações de fala e pensamento, e no caso dos recordatórios também de marcas de tempo e espaço ou narração em terceira pessoa - e o texto imagético dos desenhos, na qual não seria correto estabelecer uma relação de precedência ou hierarquia clara entre um e outro (RAMOS, 2009; POSTEMA, 2018; WOLK, 2007), temos alguma descrição verbal, mas a parcela mais significativa da ambientação e caracterização das experiências recai sobre a construção imagética das obras. 


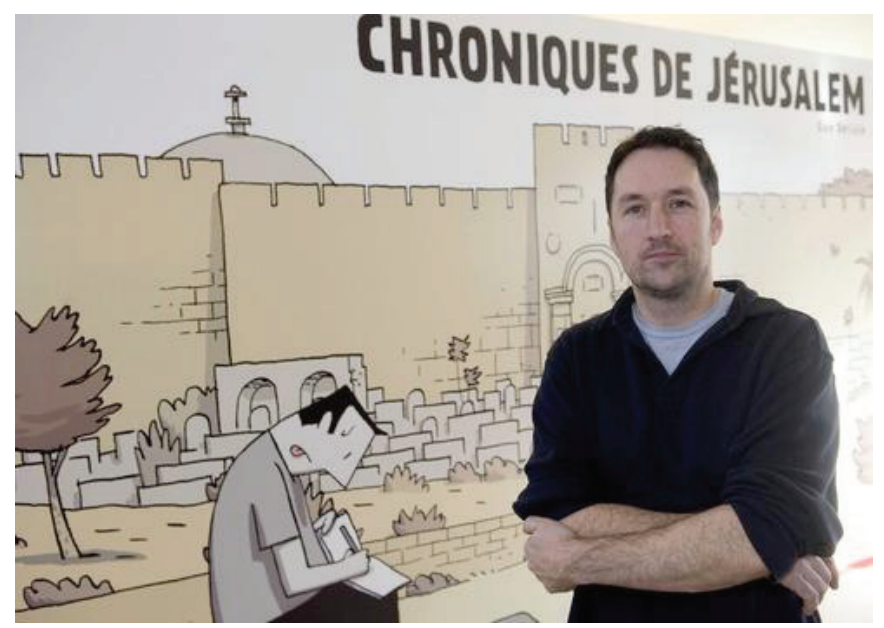

Figura 10: Guy Delisle e sua autorepresentação cartunesca: estratégia estilística para representação e interpretação da realidade que evidencia sua artificialidade.

Nesse sentido, em vez de estimular uma representação visual por meio das narrações e descrições, os quadrinhos apresentam ao leitor uma representação acabada, construída a partir dos desenhos - de modo análogo a como uma peça audiovisual ou um texto acompanhado de imagem oferecem a reconstrução fotográfica de lugares, pessoas e acontecimentos. Há, porém, uma distinção que coloca os gêneros de quadrinhos e os gêneros audiovisuais em extremos opostos: enquanto os linguagens audiovisuais como a cinematográfica, a partir de convenções definidas historicamente, buscam recriar uma sensação ilusória de naturalidade e continuidade a partir de captura de fragmentos de ações (XAVIER, 2005), os quadrinhos evidenciam e escancaram sua artificialidade ao oferecer como superfície de contato e mediação entre o leitor e a realidade experienciada o desenho, com traços que variam entre a estilização cartunesca, a tentativa de reprodução naturalista e composições sujas, confusas, por vezes quase amadoras.

O estilo gráfico de cada desenhista é um elemento essencial que influencia na recepção de uma obra, nas respostas e questionamentos que a leitura oferecerá ao público. Entre os quadrinhos de não-ficção de caráter autobiográfico (ZOUVI, 2016; VILELA, 2016 estabeleceu-se, por um lado, uma convenção em adotar-se estilos cartunescos que, novamente, evidenciam a artificialidade e um certo grau de distanciamento entre a representação autoral 
e os acontecimentos tal qual transcorreram - talvez partindo do princípio da parcialidade e da falibidade da memória (WOLK, 2007), buscando destacá-la em vez de mascará-la. Há casos excepcionais em que texto e imagem são criados por sujeitos distintos, como na série American Splendor, com textos de Harvey Pekar a respeito de seu próprio cotidiano, e traços de diversos e bastante distintos desenhistas, dentre eles o renomado quadrinista underground Robert Crumb - nesse caso, há ainda uma outra camada interpretativa e mediadora, na qual o artista gráfico apresenta sua leitura, sua interpretação acerca de Harvey Pekar, das pessoas que o rodeiam e dos pequenos eventos de suas vidas.

A camada mediadora do traço impõe um certo limite à fidedignidade - e por vezes mesmo à credibilidade - dos quadrinhos de não ficção e desse modo alguns autores, especialmente aqueles que exercem trabalhos de natureza jornalística (RAMOS, 2016) buscam de forma ocasional ou mesmo integral adotar um traço mais naturalista, que seja entendido enquanto reprodução figurativa - quase objetiva - dos acontecimentos, buscando preservar os aspectos mais documentais (MUANIS, 2013) de suas narrativas.

Esse incômodo com as limitações da representação gráfica - ou suas consequências para a fruição e recepção das obras - leva alguns autores até mesmo a adotar o uso de fotografias como referência ou mesmo modelo para a composição de alguns quadros e cenas em suas obras - temos como exemplo autores de tradições e intencionalidades bastante distintas, como a memorialista norte-americana Alison Bechdel e o jornalista de guerra maltês Joe Sacco (ZOUVI, 2016; WOLK, 2007; RAMOS, 2016). Essa preocupação é até mesmo objeto de perfomance nas graphic novels autobiográficas de Bechdel, quando a cartunista altera seu traço para indicar quando está buscando representar um documento ou fotografia, tornando-o mais austero e menos cartunesco, embora ainda estilizado, ou mesmo em um momento de Você é Minha Mãe? no qual evidencia, num gesto metalinguístico, o uso que faz de registros documentais para a composição do desenho (Figuras 11 e 12).

Em Crônicas de Jerusalém, em contrapartida, Guy Delisle frequentemente representa a si próprio desenhando lugares e edifícios in loco, diante deles próprios, munido de seu bloco de desenho. Em uma cena específica (Figuras 13 e 14), o quadrinista empreende vários esforços para registrar dessa maneira um campo de refugiados murado, é expulso dali, mas estaciona a uma distância segura para continuar o trabalho. Esses momentos, no entanto, ganham uma dimensão até certo ponto satírica se justapostos com os esforços 

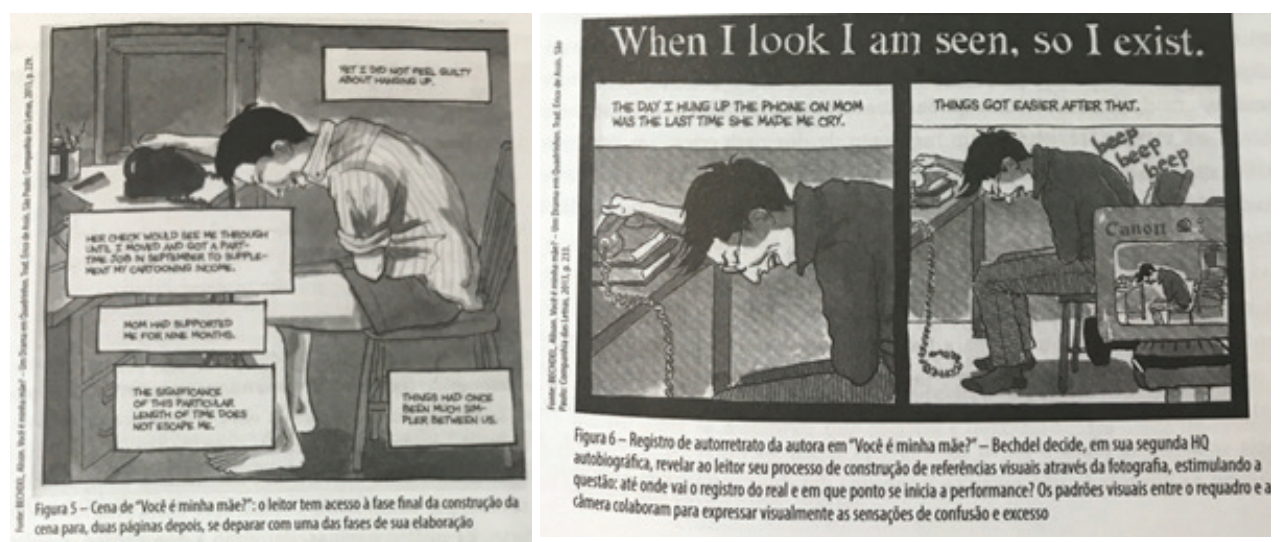

Figuras 11 e 12: Em Você é Minha Mãe?, Alison Bechdel realiza um movimento de distanciamento entre a experiência e a performance, ao distinguir a reprodução fotográfica (ainda estilizada) da representação cartunesca. (ZOUVI, 2016, p.73)
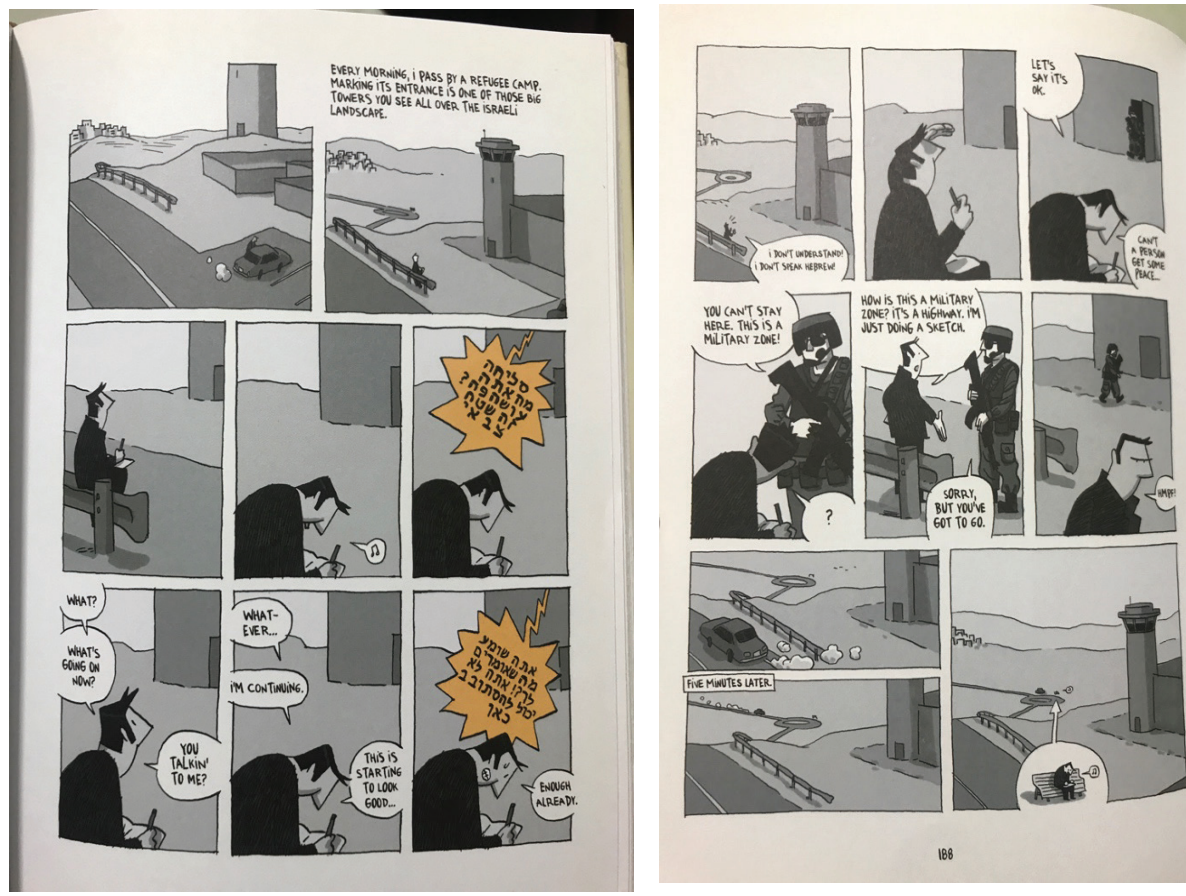

188

Figuras 13 e 14: Em Crônicas de Jerusalém, Delisle registra diversas vezes sua preocupação em reproduzir in loco o desenho de edifícios.

Só temos acesso à representação cartunesca, no entanto. 
de reprodução - e performáticos - de Joe Sacco e Alison Bechdel, uma vez que em momento algum há uma ruptura com o estilo de desenho adotado, a tentativa de apresentar um traço mais naturalista, documental. Desse modo, o cartunista assume estilisticamente o aspecto subjetivo, interpretativo, de seu proceder narrativo.

A análise dos quadrinhos de não ficção deve, assim, levar sempre em conta que a camada verbal é apenas uma das dimensões textuais-discursivas das obras, e que os desenhos são uma camada de narração e representação de igual importância. É sempre necessário, ainda, distinguir aquilo que compõe o estilo, isto é, aquilo que é intrínseco à individualidade da representação gráfica de cada autor, o modo como assimilam a realidade e a renderizam na forma de desenho, o que inclui sua autorepresentação (Figura 10), e gestos que deliberadamente constituem intervenções sobre a realidade.

Assim, a fruição e a análise crítica dos quadrinhos de viagem - assim como os autobiográficos e jornalísticos - demandam o estabelecimento de um tipo singular de pacto de leitura que dê conta de lidar simultaneamente com o caráter não ficcional dessas narrativas e com a ficcionalidade e exaustiva interpretação de lugares, sujeitos e ações. Nessa direção, podemos retomar proposta de David Eason (1990) para classificar os autores do Novo Jornalismo, a vertente do jornalismo literário norte-americano surgida e exercida ao longo da década de 1960: Eason propõe uma divisão entre "realistas" (a quem também podemos chamar de empiricistas), que acreditam conseguir manter distância da realidade material, enxergá-la e narrá-la objetivamente, e os "modernistas" (a quem também podemos denominar fenomenólogos), que se vêem como intérpretes da realidade e não descolam a narração de um movimento subjetivo, interpretativo no qual a realidade em si é inacessível, sempre filtrada a partir da cultura e ideologia de observadores e atores, sujeita a certo grau de ficcionalização em sua apreensão. Em ambos os casos, é preciso notar, a realidade é algo interpretado e em certo grau ficcionalizado pelos sujeitos - ao menos a partir de uma organização lógica e estruturada de ações e acontecimentos, com o estabelecimento de relações causais entre eles-; porém, há autores que buscam, dentro dos recursos narrativos que têm à disposição, reforçar a verossimilhança e negar ou mascarar as camadas de interpretação e ficcionalidade, enquanto outros assumem a inevitabilidade dessas camadas e a impossibilidade da compreensão e da reprodução objetivas da realidade.

Enquanto autores como Joe Sacco e Alison Bechdel estão em distintas zonas cinzentas entre esses dois polos, acredito ser possível afirmar que Guy Delisle, ao menos nos aspectos visuais de suas obras, encontre-se mais próximo do polo modernista - inclusive pelo caráter episódico, fragmentário de suas narrativas que torna sua experienciação menos "natural" (XAVIER, 
2005), novamente chamando a atenção à artificialidade do ato narrativo. Se em certos momentos um traço cartunesco bastante estilizado é adotado para expressar a irritação de um dos líderes dos Médicos Sem Fronteiras ao passar por uma guarida de fronteira e ter de se despir quase completamente no processo de revista (Figura 16) - imprimindo certo humor a uma situação de violência -, em um quadro de Pyongyang, um dos únicos quadros de página inteira de suas obras, o que imprime mais impacto à cena, representa uma dezena de meninas norte-coreana que tocavam acordeon numa apresentação televisionada. Seu espanto com a uniformização das ações e das expressões sorridentes treinadas, quase sinceras, o leva a compor o visual da cena ao conferir feições quase idênticas às crianças (Figura 15). Assim, mesmo em sua fase de maior preocupação denuncista e menor grau de alteridade, Delisle assume-se como autor e intérprete da realidade, estabelecendo certo pacto com o leitor que permite demarcar certas distâncias entre eles, e à narrativa o aspecto de reconstrução pessoal da experiência, em vez de reprodução fidedigna da realidade.
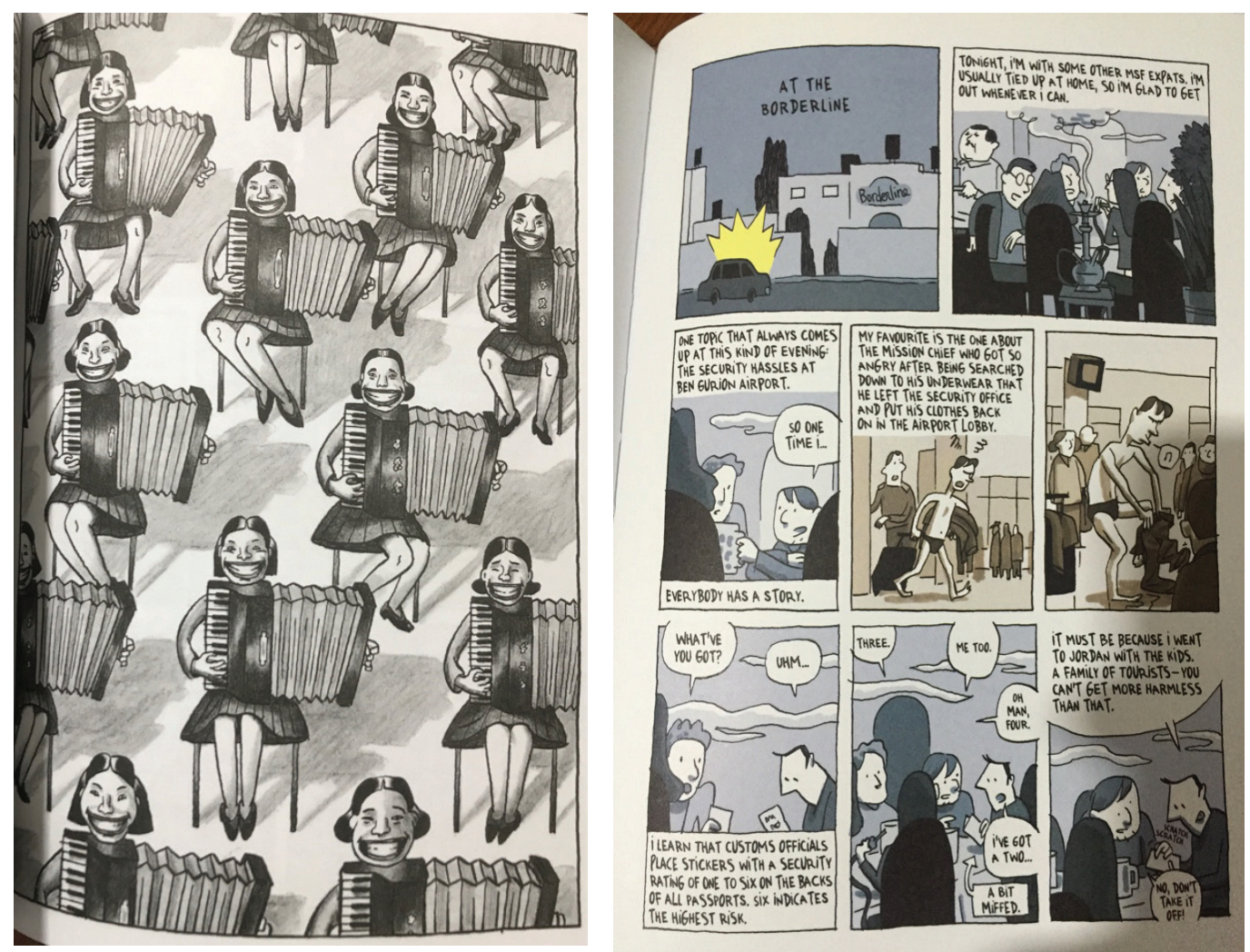

Figuras 15 e 16: Cenas de Pyongyang (à esquerda) e Crônicas de Jerusalém (à direita): o traço cartunesco se evidencia como artificialidade, interpretação do real, e demanda novo pacto de leitura. 


\section{REFERÊENCIAS}

AUGÉ, Marc. Não-lugares. Introdução a uma antropologia da sobremodernidade. 4. ed. Campinas: Papirus, 1994.

BAK, John S. Introduction. In: BAK, John S. (Org.); REYNOLDS, Bill (Org.). Literary Journalism Across the Globe. Amherst: University of Massachussetts Press, 2011, p.1-20.

BAKHTIN, Mikhail. Os Gêneros do Discurso. São Paulo: Editora 34, 2016.

BAKHTIN, Mikhail. Problemas da Poética de Dostoiévski. 5. ed. Rio de Janeiro: Forense Universitária, 2010.

BENJAMIN, Walter. Experiência e Pobreza. In: BENJAMIN, Walter. O Anjo da História. Belo Horizonte: Autêntica, 2012, loc.1210-1320 (ebook)

BENJAMIN, Walter. O contador de histórias: reflexões sobre a obra de Nikolai Leskov. In: BENJAMIN, Walter. Linguagem, Tradução, Literatura (Filosofia, Teoria e Crítica). Belo Horizonte: Autêntica, 2018, loc.2304-2766 (ebook)

CERTEAU, Michel de; GIARD, Luce; MAYOL, Pierre. A Invenção do Cotidiano. v.2. Morar, cozinhar. 12. ed. Petrópolis: Vozes, 2013.

DALMONTE, Edson Fernando; ARAUJO, Tiago Canário de. Viagem a Shenzhen: construção discursiva na obra de Guy Delisle. Revista Famecos, v. 18, n.2, p.348-372, 2011.

DELISLE, Guy. Crônicas Birmanesas. Campinas: Zarabatana, 2009a.

DELISLE, Guy. Jerusalem. Chronicles from the Holy City. Montréal: Drawn \& Quarterly, 2012.

DELISLE, Guy. Pyongyang. Uma viagem à Coréia do Norte. Campinas: Zarabatana, 2007.

DELISLE, Guy. Shenzhen. Uma viagem à China. Campinas: Zarabatana, 2009b.

EASON, David. The New Journalism and the Image-World. In: SIMS, Norman (Org.). Literary Journalism in the Twentieth Century. Oxford: Oxford University Press, 1990, p.191-205

GENRO FILHO, Adelmo. O Segredo da Pirâmide. Florianópolis: Insular, 2012.

HARTSOCK, John. Literary Journalism and the Aesthetics of Experience. Amherst: University of Massachussetts Press, 2016.

HELlER, Agnes. O Cotidiano e a História. São Paulo: Paz e Terra, 2016. (ebook)

MARTINEZ, Monica. Jornalismo Literário: tradição e inovação. Florianópolis: Insular, 2016.

MARTINEZ, Monica; PASSOS, Mateus Yuri. Gonzo Brazilian Style: Arthur Veríssimo's adaptations of Thompson's journalism. In: ALEXANDER, Robert (Org.); ISAGER, Christine (Org.). Fear and Loathing Worldwide: Gonzo Journalism beyond Hunter S. Thompson. Londres: Bloomsbury, 2018, p.69-83.

MUANIS, Felipe. O quadrinho documental e a tradução da cidade. 9a Arte, v.2, n.1, p.45-57, 2013.

PAPAVERO, Nelson; TEIXEIRA, Dante Martins. A fauna de São Paulo nos séculos XVI a XVIII, nos textos de viajantes, cronistas, missionários e relatos monçoeiros. São Paulo: EdUSP, 2007.

PASSOS, Mateus Yuri. De fontes a personagens: definidores do real no jornalismo literário. In: SOSTER, Demétrio de Azeredo (Org.); PICCININ, Fabiana Quatrin (Org.). Narrativas Midiáticas Contemporâneas: perspectivas epistemológicas. Santa Cruz do Sul: Catarse, 2017.

PASSOS, Mateus Yuri; CASTILHO, Fernanda. Pessoas de paisagem: a caracterização de destinos portugueses na revista Fugas. Rizoma, v.5, n.1, p.111-123, 2017. 
POSTEMA, Barbara. Estrutura Narrativa nos Quadrinhos. Construindo sentido a partir de fragmentos. São Paulo: Peirópolis, 2018.

RAMOS, Paulo. A leitura dos quadrinhos. São Paulo: Contexto, 2009.

RAMOS, Paulo. Jornalismo em Quadrinhos ou Quadrinhos com Jornalismo? In: VERGUEIRO, Waldomiro (Org.); RAMOS, Paulo (Org.); CHINEN, Nobu (Org.). Enquadrando o Real. São Paulo: Criativo, 2016, p. 196-229.

VILELA, Túlio. Aspectos (Auto)Biográficos nas Histórias em Quadrinhos. In: VERGUEIRO, Waldomiro (Org.); RAMOS, Paulo (Org.); CHINEN, Nobu (Org.). Enquadrando o Real. São Paulo: Criativo, 2016, p. $10-43$.

VOLÓSHINOV, Valentin. Marxismo e Filosofia da Linguagem. São Paulo: Editora 34, 2015.

WOLK, Douglas. Reading Comics. How graphic novels work and what they mean. Cambridge: Da Capo Press, 2007.

XAVIER, Ismail. O discurso cinematográfico: a opacidade e a transparência. 3. ed. São Paulo: Paz e Terra, 2005.

ZOUVI, Aline de Alvarenga. Auto-Obsessão versus Representatividade nos Quadrinhos de Alison Bechdel. In: VERGUEIRO, Waldomiro (Org.); RAMOS, Paulo (Org.); CHINEN, Nobu (Org.). Enquadrando o Real. São Paulo: Criativo, 2016, p. 60-77. 